\title{
Projeto de Produção e Processo de Pré-fabricação de Componentes de Bambu
}

\author{
Marco Antônio dos Reis Pereira ${ }^{1}$, Henrique Bragato Carrara ${ }^{2}$, \\ Tomas Queiroz Ferreira Barata ${ }^{2}$, Ivaldo de Domenico Valarelli ${ }^{1}$, \\ Maximiliano dos Anjos Azambuja ${ }^{1}$ \\ ${ }^{1}$ Faculdade de Engenharia de Bauru - FEB, Universidade Estadual Paulista - UNESP
}

${ }^{2}$ Faculdade de Arquitetura, Artes e Comunicação - FAAC, Universidade Estadual Paulista - UNESP

\begin{abstract}
RESUMO
O projeto e o processo de produção do galpão oficina em Bambu apresentado neste trabalho é fruto de quase dois anos de cooperação junto à Associação de Agricultores Viverde, Universidade Estadual Paulista e Unisol. O sistema é composto de pilares de aroeira roliça, estrutura de cobertura formada por pórticos em bambu in natura e conexões metálicas. $\mathrm{O}$ desenvolvimento do detalhamento das peças e ligações, por meio de desenhos técnicos de cada componente, permitiu a elaboração de encaixes com precisão e padronização com vistas à otimização da execução, economia de tempo, de matéria-prima e de energia na linha de montagem. Nesse processo, fez-se necessário a criação e o aprimoramento de gabaritos para facilitar a montagem das peças. Foram registradas as etapas de montagem dos componentes junto ao Laboratório Experimental de Bambu e Processamento de Madeiras da UNESP/FEB. Os resultados obtidos permitem concluir o bom desempenho do processo de pré-fabricação de componentes de Bambu.
\end{abstract}

Palavras-chave: sustentabilidade, conexões, detalhes de encaixes.

\section{Production Design and Pre-fabrication Process of Bamboo Components}

\begin{abstract}
The design and production process of the workshop shed made of bamboo presented in this paper is the result of almost two years of cooperation between "Viverde" Farmers Association, "Universidade Estadual Paulista" and "Unisol". The system consists of rounded aroeira pillars, a roof structure formed by in natura bamboo frames and metal connections. The development of the parts and connections detailing, through the technical drawing of each component, enabled the development of standardized precision fittings aiming at optimizing the execution and saving time, energy and raw material on the assembly line. In this process, the creation and improvement of templates was necessary in order to facilitate the assembly of parts. The component assembly phases were recorded at the Experimental Laboratory for Bamboo and Wood Processing - UNESP/FEB. The results showed the good performance of the pre-fabrication process of bamboo components.
\end{abstract}

Keywords: sustainability, connections, fitting details. 


\section{INTRODUÇÃO}

A construção e o uso de edificação são as principais causas da demanda de energia e de materiais que produzem gases de efeito estufa. Para reduzir e então reverter com sucesso o aquecimento global e o esgotamento dos recursos naturais no planeta, a construção civil encara novos desafios, tanto no que se refere ao emprego de materiais renováveis de base florestal, como no tocante à forma de pré-fabricação de componentes estruturais que utilizem técnicas menos impactantes para o meio ambiente (Keeler, 2010).

$\mathrm{O}$ uso do bambu in natura como material de construção pode ser considerado como uma alternativa viável ao uso abusivo do aço e do concreto; seu emprego também pode favorecer a redução da pressão sobre o uso de madeira proveniente de florestas nativas e plantadas. $\mathrm{O}$ bambu apresenta uma admirável vitalidade, uma grande versatilidade, leveza, resistência e facilidade de ser trabalhado com ferramentas manuais simples, qualidades que têm lhe proporcionado o mais longo e variado papel na evolução da cultura humana, quando comparado com qualquer outro tipo de planta (Farrely 1984 apud Pereira \& Beraldo 2008). Em relação às suas propriedades estruturais, quando relacionado à sua resistência/massa específica e rigidez/massa específica, os valores se equiparam à madeira e ao concreto, podendo ser comparado relativamente ao aço (Janssem, 2000). Construções têm sido executadas com o uso do Bambu segundo Vélez (2000), além de sistemas mistos, com materiais lignocelulósicos de acordo com Barata \& Gandini (2006). Este trabalho apresenta o projeto de produção e o processo de pré-fabricação de componentes construtivos com bambu in natura. Aborda a atividade de projeto com fundamentação técnica e busca sistematizar as atividades práticas relativas às etapas de produção dos componentes em unidade de pré-fabricação.

\section{MATERIAIS E MÉTODOS}

A metodologia adotada no trabalho se enquadra em uma pesquisa-ação, um dos inúmeros tipos de investigação-ação que, de uma maneira genérica, promove uma abordagem de processo que gera um ciclo no qual se aprimora a realidade pela oscilação sistemática entre agir no campo da prática e analisar a respeito dessa prática (Tripp, 2005). Em outras palavras, a investigação-ação se baseia em uma tentativa continuada, sistemática e empiricamente fundamentada de aprimorar a prática. Thiollent (1986) aponta que a pesquisa-ação pode ser utilizada quando há simultaneidade entre a pesquisa e a resolução (ação) de um problema coletivo, no qual pesquisadores, projetistas, mão de obra e demais atores estejam envolvidos de modo cooperativo ou participativo. A maioria dos processos que visa a incrementar melhorias ou promover aumento de qualidade em projetos e produtos segue o seguinte ciclo: a) planejar uma solução; b) agir para implantar a melhora planejada; d) monitorar e descrever os efeitos da ação; d) avaliar os resultados da ação e sua eficácia. A Figura 1 apresenta a representação de um ciclo básico de investigação-ação adaptado para a pesquisa.

A sistematização do processo de pré-fabricação dos componentes estruturais que compõem o sistema construtivo se dividiu em duas etapas: 1) elaboração do projeto executivo de produção; e 2) implantação do processo produtivo dos componentes préfabricados. Para a definição da concepção estrutural

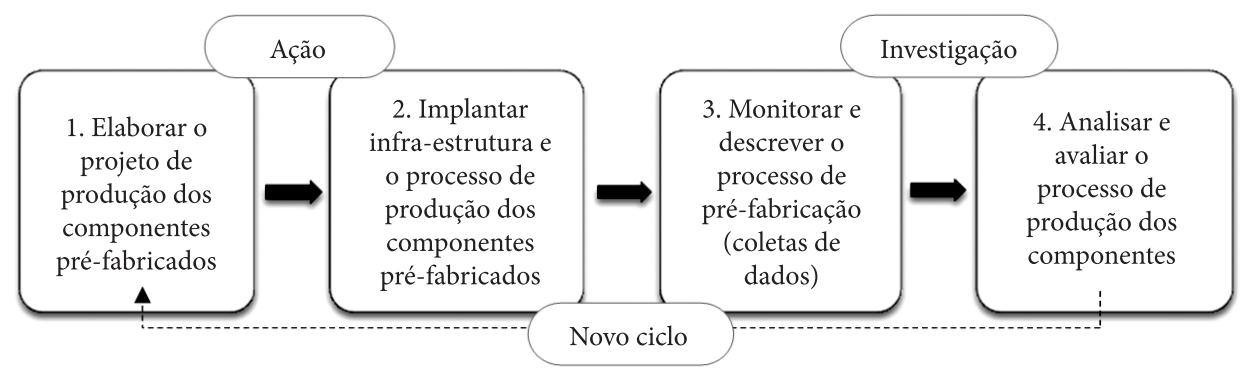

Figura 1. Ciclo de investigação-ação implantado no trabalho (adaptado de Tripp, 2005).

Figure 1. Cycle of action inquiry implemented in the work (adapted from Tripp, 2005). 
do galpão oficina e dos respectivos componentes pré-fabricados, foram geradas imagens $3 \mathrm{D}$ em perspectivas por meio do software Sketchup. O projeto executivo foi elaborado com o auxílio do software AutoCad para a confecção das pranchas de produção dos componentes estruturais e todo o detalhamento e codificação das peças e interfaces.

Depois da etapa de elaboração do projeto executivo de produção, iniciou-se a etapa de pré-fabricação na área agrícola do Laboratório Experimental de Bambu e Processamento de Madeiras da UNESP/FEB Bauru/SP. Nesse local, foram confeccionados e instalados gabaritos para a produção dos componentes estruturais préfabricados. Antes de iniciar o processo de préfabricação, ocorreu a adaptação do fluxo de trabalho que compreendeu a separação das peças, transporte para os gabaritos de produção e estocagem dos componentes montados. Durante o processo de pré-fabricação, foram realizados procedimentos de coletas de dados que compreenderam catalogação, descrição e registro fotográfico das distintas etapas de produção.

\section{RESULTADOS E DISCUSSÕES}

Para a melhor sistematização e análise dos resultados apresentados no trabalho, dividiu-se o processo de pré-fabricação dos componentes em três subetapas: 1) Diretrizes gerais do projeto arquitetônico; 2) Projeto executivo de pré-fabricação das vigas triplas e dos pilares duplos inclinados; e 3) Desenvolvimento do processo de pré-fabricação dos componentes.

\subsection{Diretrizes gerais do projeto arquitetônico}

O projeto do Galpão Oficina foi desenvolvido por uma equipe composta de moradores da comunidade rural, alunos de graduação, arquitetos, engenheiros e professores da UNESP/FEB Bauru/SP. Possui como diretriz arquitetônica a implantação de um espaço de $320 \mathrm{~m}^{2}$ de área coberta para fins de trabalho e reunião de um grupo de agricultores familiares chamado Viverde. A obra foi realizada dentro do assentamento rural Horto de Aimorés, localizado na cidade de Pederneiras/SP, próximo à divisa com o município de Bauru. O programa de necessidades do projeto prevê uma área de atividades de marcenaria que abrigará máquinas para o processamento do bambu e uma sala para a administração da oficina e reuniões do grupo. A Figura 2 mostra uma imagem em perspectiva da estrutura do galpão oficina.

A estrutura do Galpão Oficina é composta por pórticos produzidos com bambu in natura fixados através de conectores metálicos nos pilares roliços de aroeira. A estrutura de cobertura é composta de nove pórticos montados a partir de dois componentes pré-fabricados principais, as vigas triplas e os pilares duplos inclinados. Os pórticos possuem um vão entre apoios de $8,25 \mathrm{~m}$ de distância e são fixados nas partes superiores dos pilares de aroeira, estes foram enterrados a 5,0 $\mathrm{m}$ de profundidade e alinhados a 3,0 m de distância. A Figura 3 apresenta o corte transversal da estrutura com indicação dos componentes e peças.

\subsection{Projeto executivo de pré-fabricação das vigas triplas e dos pilares duplos inclinados}

O projeto executivo de produção dos elementos estruturais foi elaborado em dois componentes estruturais principais: a) projeto das vigas triplas; e b) projeto dos pilares duplos inclinados. Para a estrutura do Galpão Oficina, foram produzidas 18 componentes viga tripla e 18 pilares duplos inclinados. Cada peça que compõe o componente recebeu um código, usado para o armazenamento e controle da quantificação dos elementos. O componente viga tripla é formado por sete peças de bambu in natura de 12,0 cm de diâmetro médio unidos por barras roscadas passantes de $3 / 8$ " de espessura (Figura 4).

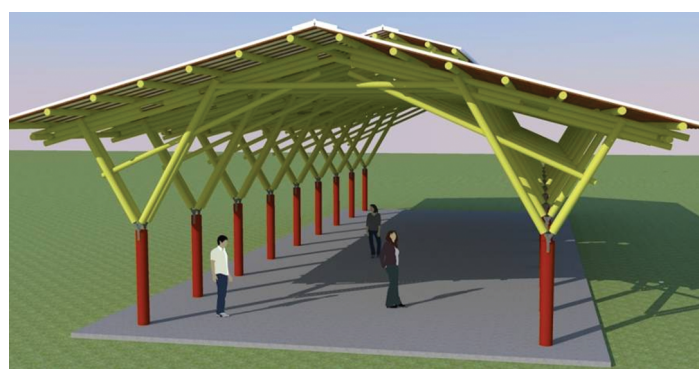

Figura 2. Imagem perspectiva da estrutura do galpãooficina.

Figure 2. Image view of the structure of the shedworkshop. 


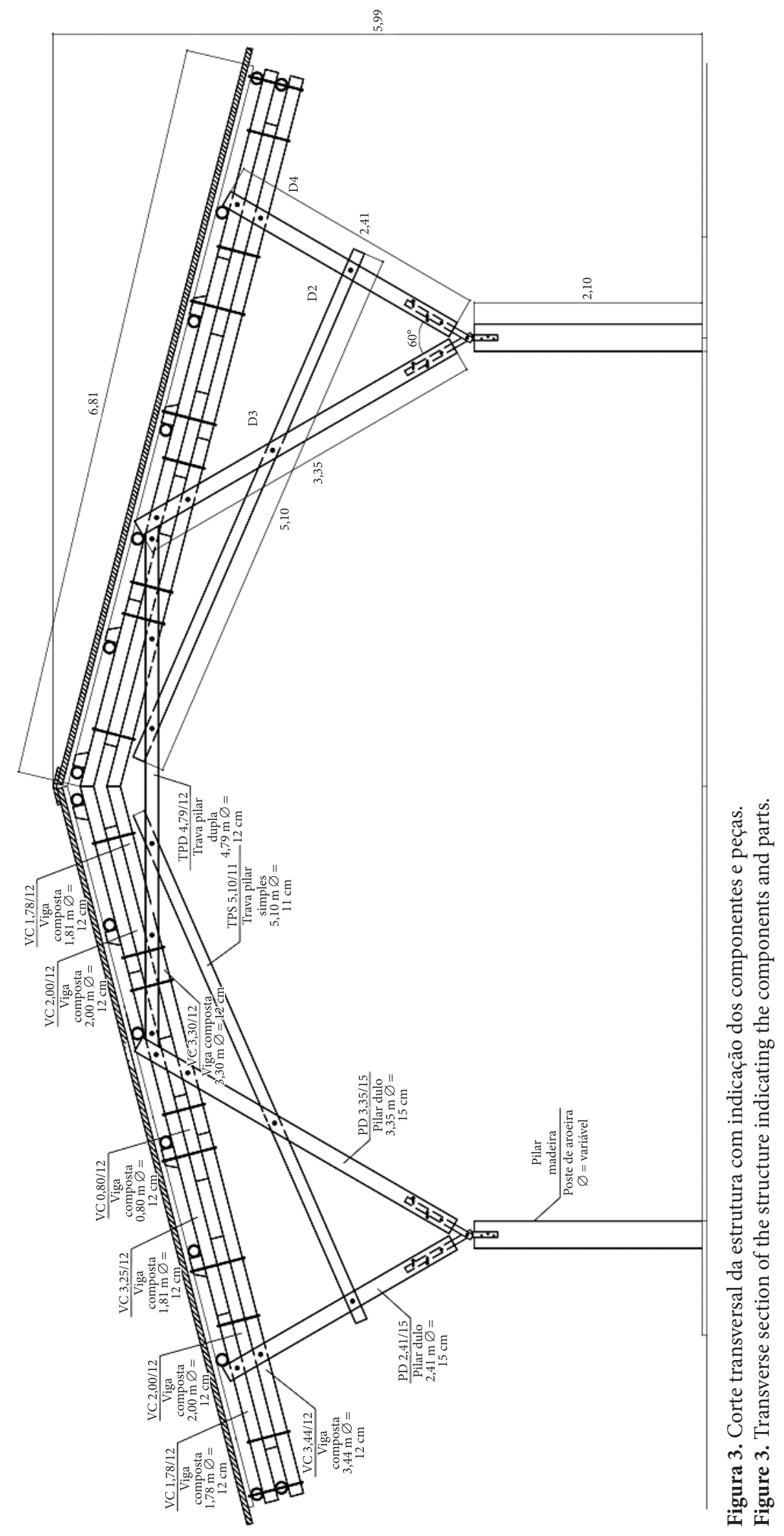


O componente pilar duplo inclinado é formado por cinco peças de bambu in natura. As peças $\mathrm{PD} 3.35 / 15$ e PD 2.41/15 possuem diâmetro médio de $15,0 \mathrm{~cm}$, a peça TPS 5.10/11 tem diâmetro médio de $11,0 \mathrm{~cm}$. Estas são unidas por barras roscadas de 1/2" de espessura. Na base dos pilares, é fixado o conector metálico para a ligação com os pilares roliços de aroeira (Figura 5).

\subsection{Desenvolvimento do processo de pré- fabricação dos componentes}

A pré-fabricação dos componentes foi realizada por um carpinteiro profissional e dois ajudantes com experiência na elaboração de produtos em bambu.
Além da coordenação geral do projeto, esta etapa contou também com o efetivo acompanhamento e orientação dos arquitetos envolvidos no desenvolvimento do projeto arquitetônico e executivo, do engenheiro civil calculista e alunos voluntários que integram o Grupo Taquara da UNESP/FEB Bauru/SP. Esta etapa dividiu-se em: 1) Corte dos colmos; 2) Tratamento preservativo; 3) Execução da conexão metálica no pilar de bambu; e 4) Pré-fabricação das vigas duplas e dos pilares duplos inclinados.

\subsubsection{Corte dos colmos}

O corte dos colmos foi o procedimento inicial da pré-fabricação. Foram escolhidas as peças mais

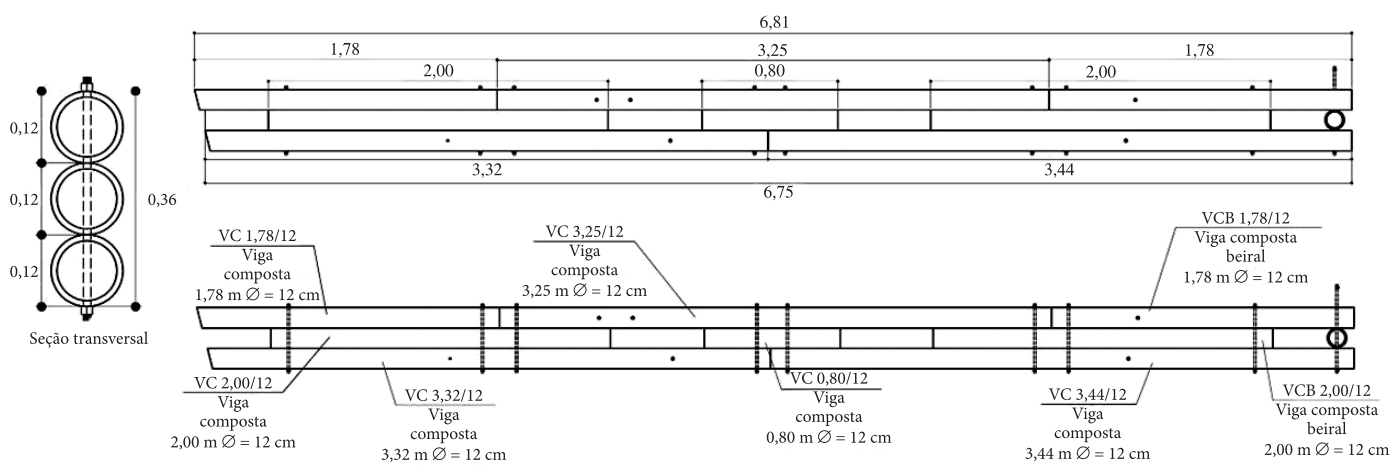

Figura 4. Elevações e seção transversal da viga tripla com indicação das peças.

Figure 4. Elevation and cross section showing the triple beam parts.

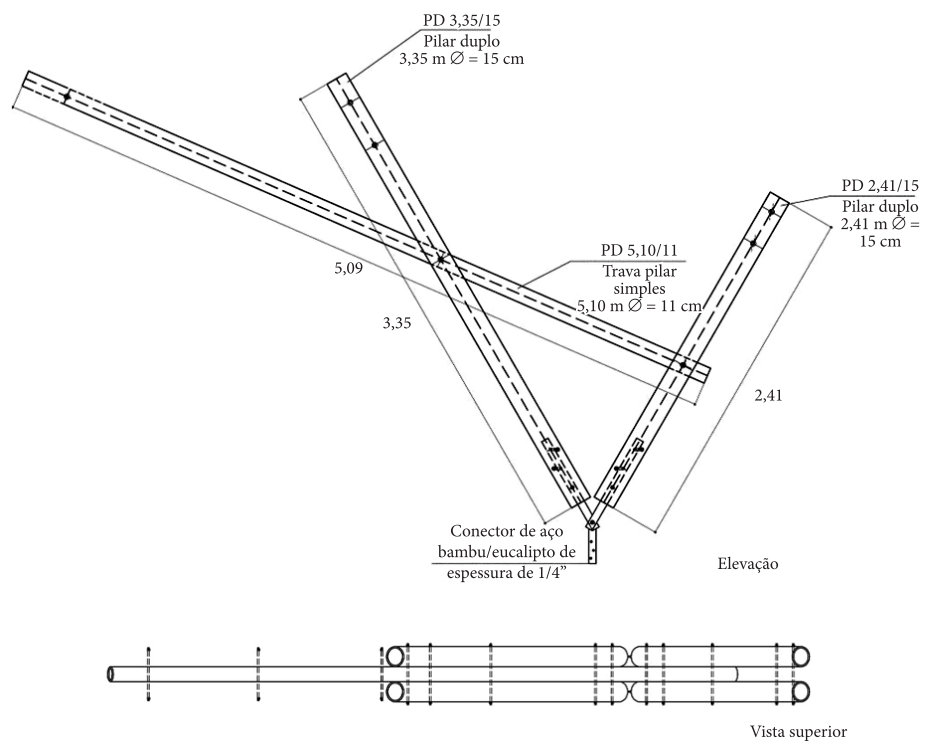

Figura 5. Elevações e vista superior dos pilares duplos inclinados.

Figure 5. Elevations and plan view of the double inclined columns. 
retilíneas e sem defeitos através de uma seleção visual. Estas foram separadas e cortadas nos tamanhos brutos, com uma margem de erro médio de $50,0 \mathrm{~cm}$ devido a peculiaridades do material. As peças brutas foram codificadas, quantificadas e armazenadas adequadamente, seguindo o romaneio de controle de produção (Tabela 1).

\subsubsection{Tratamento preservativo das peças de bambu in natura}

No tratamento preservativo inicial, foi utilizada a técnica do Boucherie com solução de Borax. Porém, uma complementação do tratamento utilizando uma técnica de injeção de PENTOX $^{\circledR}$ nos entrenós foi realizada. Este procedimento consiste em furar com uma furadeira todos os nós das peças de bambu, em seguida, aplicar em cada furo o produto através de um borrifador com uma ponta adaptada. Por último, todos os furos e rachaduras foram vedados com uma mistura de cola branca com serragem de bambu.

\subsubsection{Execução da conexão metálica no pilar de bambu}

A preparação dos pilares de bambu demandou um trabalho especial no projeto, pois, na base do pilar, foi fixada uma chapa metálica com o auxílio de parafusos e graute. Essa chapa faz conexão do pórtico de bambu com os pilares de aroeira. O Quadro 1 apresenta as etapas de execução e a análise do processo de execução da conexão metálica no pilar de bambu.

\subsubsection{Pré-fabricação das vigas triplas e dos pilares duplos inclinados}

A partir do projeto executivo de produção e de montagem, foi planejada a etapa de execução dos componentes estruturais com o auxílio de equipamentos manuais elétricos, bancadas de apoio e gabaritos de pré-fabricação. Essa infraestrutura favoreceu um processo de pré-fabricação mais ágil e preciso dos componentes. A seguir, são apresentadas as etapas de montagem da viga tripla e dos pilares duplos inclinados.

\subsubsection{Pré-fabricação das vigas triplas}

O gabarito das vigas triplas foi montado sobre 10 peças de andaimes, nos quais placas de madeira compensada reutilizadas foram apoiadas em forma de bancada. O gabarito possui uma longarina lateral, que serve para locação e a marcação de onde devem ser feitos os furos nas peças. Na montagem das vigas, trabalharam sempre três colaboradores. $\mathrm{O}$ Quadro 2 mostra a sequência de trabalho e a análise do processo de execução.

\subsubsection{Pré-fabricação dos pilares inclinados duplos}

O gabarito dos pilares duplos inclinados foi montado do lado de fora do barracão, devido ao seu

Tabela 1. Codificação e quantificação para controle das peças de bambu.

Table 1. Coding and quantification for control of pieces of bamboo.

\begin{tabular}{|c|c|c|c|c|}
\hline Tipo & Código & Diâmetro (m) & $\begin{array}{c}\text { Comprimento } \\
\text { líquido (m) }\end{array}$ & Quantidade \\
\hline \multirow{2}{*}{ Pilares } & (PD 2.41/15) & $\varnothing 0,14$ - $\varnothing 0,16$ & 2,41 & 36 \\
\hline & (PD 3.35/15) & $\varnothing 0,14-\varnothing 0,16$ & 3.35 & 36 \\
\hline \multirow{8}{*}{ Vigas } & (VCB 1.78/12) & $\varnothing 0,11-\varnothing 0,13$ & 1,78 & 18 \\
\hline & (VCB 2.00/12) & $\varnothing 0,11-\varnothing 0,14$ & 2,00 & 18 \\
\hline & (VC 3.25/12) & $\varnothing 0,11-\varnothing 0,13$ & 3,25 & 18 \\
\hline & (VC 1.78/12) & $\varnothing 0,11-\varnothing 0,13$ & 1,78 & 18 \\
\hline & (VC 2.00/12) & $\varnothing 0,11$ - Ø 0,13 & 2,00 & 18 \\
\hline & (VC 0.80/12) & $\varnothing 0,11-\varnothing 0,13$ & 0,80 & 18 \\
\hline & (VC 3.32/12) & $\varnothing 0,11-\varnothing 0,13$ & 3,32 & 18 \\
\hline & (VC 3.44/12) & $\varnothing 0,11-\varnothing 0,13$ & 3,44 & 18 \\
\hline \multirow{2}{*}{ Travamento } & (TPS 5.09/12) & $\varnothing 0,11$ - Ø 0,13 & 5,09 & 18 \\
\hline & (TPD 4.79/12) & $\varnothing 0,11-\varnothing 0,13$ & 4,79 & 18 \\
\hline
\end{tabular}


tamanho e também pela facilidade do manuseio do componente após a montagem. Para o adequado posicionamento e fixação dos componentes no gabarito, foram colocadas duas toras de aroeira como esperas simulando os pilares. Para auxiliar a montagem dos pilares inclinados duplos no gabarito, oito tábuas de $2,50 \mathrm{~m} \times 15,0 \mathrm{~cm}$ foram locadas $\mathrm{e}$ fixadas para o apoio de uma das faces do pórtico. A Figura 6 indica a posição do pórtico montado sobre a estrutura do gabarito de pré-fabricação.

O Quadro 3 apresenta a sequência de trabalho e a análise do processo de execução dos pilares duplos inclinados.

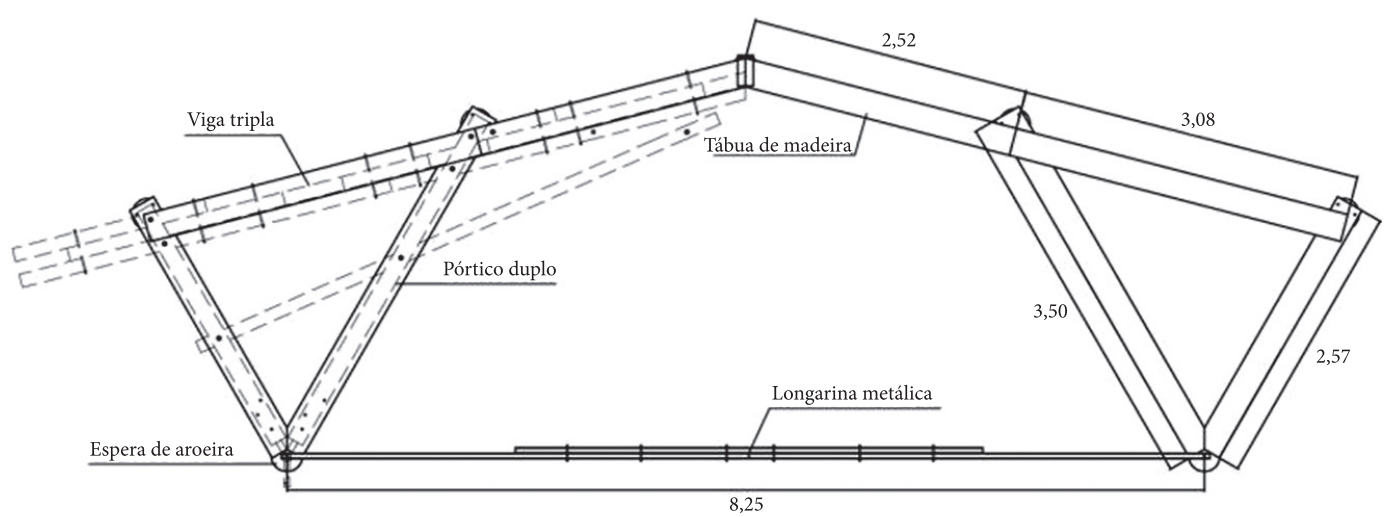

Figura 6. Projeto do gabarito dos pórticos.

Figure 6. Project of the template of the shed workshop.

Quadro 1. Etapas de execução da conexão metálica no pilar de bambu.

Chart 1. Steps for implementing the metallic connection in the bamboo pillar.

\section{Registro fotográfico}
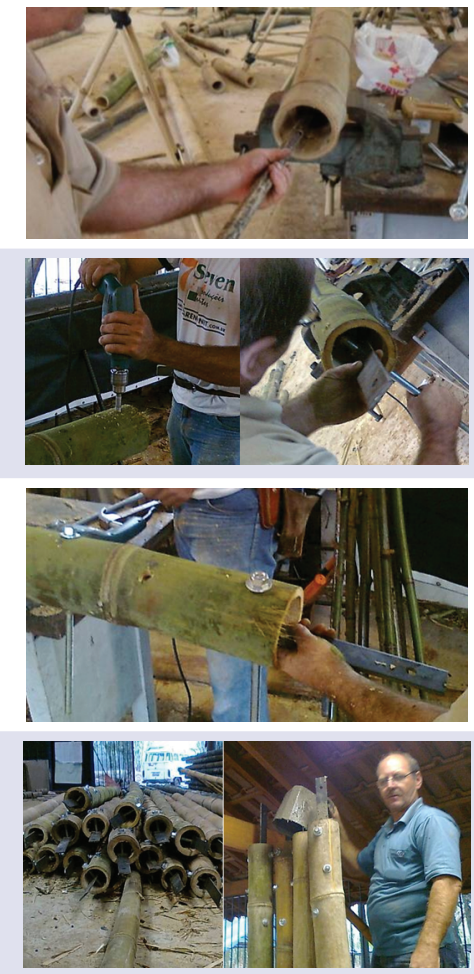

\section{Descrição das etapas}

\section{Análise do processo}

Etapa 1 - O colmo foi colocado sobre uma bancada e preso em uma morça. Depois, um dos seus diafragmas foi quebrado, para que a chapa metálica de seção $2 \times 1 / 4$ " entrasse corretamente dentro do bambu.

Etapa 2 - Com 5,0 $\mathrm{cm}$ a partir da base do pilar, foi marcado o ponto do primeiro furo passante. Depois da furação, é locada a barra roscada de 5/8" dentro do colmo.

Etapa 3 - Depois de fixada a peça metálica, outros dois furos passantes foram executados na base do pilar. Nesses furos, foram passadas barras roscadas de 1/2", travando totalmente a barra metálica.
Verificou-se que a parte interna do colmo não ficou uniforme.
Este primeiro furo serviu com guia, para deixar a peça metálica posicionada dentro do colmo, para posterior realização dos outros furos.

Foi preciso fazer dois furos para transpassar a barra roscada na diagonal pelo furo da peça metálica dentro do colmo.
Etapa 4 - Depois da fixação da chapa metálica com as barras roscadas, os pilares foram posicionados na vertical com a parte do encaixe metálico para cima e foram grauteadas.
Ocorreram dificuldades durante o preenchimento dos colmos. 
Quadro 2. Etapas de montagem das vigas triplas compostas.

Chart 2. Assembly steps of the triple composite beams.

Descrição das etapas
Análise do processo

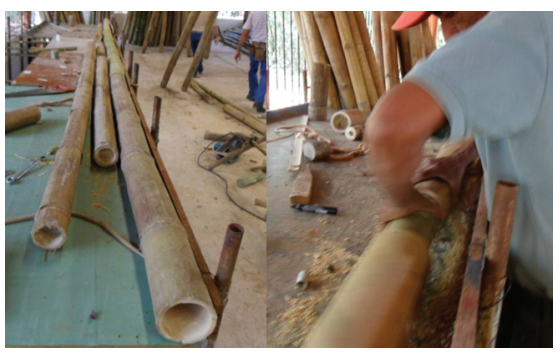

Etapa 7 - A terceira linha foi formada por 2 peças (VC 3.44/12 e VC 3;32/12). Foram locadas, alinhadas na sequência no gabarito e tiveram suas pontas, que se encontram, preenchidas com eucalipto entre as peças.
Mesmos problemas recorrentes na etapa 1 .

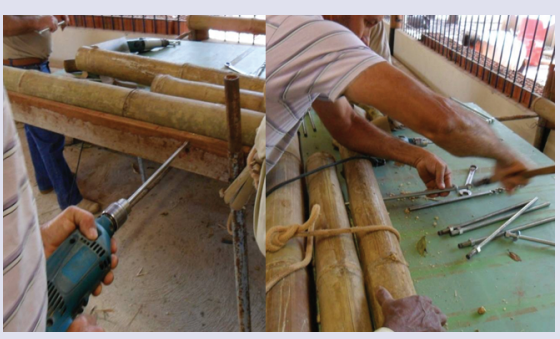

Etapa 8 - Foram amarradas e transpassadas de uma só vez. A cada furo feito, uma barra roscada de $1 / 2$ " com $0,40 \mathrm{~cm}$ de comprimento era posicionada e travada. Cada viga recebeu 8 barras de travamento.
Nesta etapa, a viga era amarrada somente próxima ao local onde será feito o furo.

Ocorreram pequenos desvios durante a montagem.

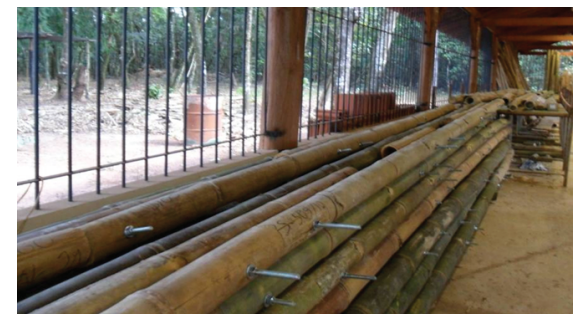

Etapa 9 - A viga tripla composta foi retirada do gabarito e transportada para a área de armazenamento.
A viga tripla foi retirada manualmente do gabarito por duas pessoas e empilhada na lateral das bancadas. 
Quadro 3. Etapas de montagem dos pórticos nos gabaritos.

Chart 3. Manufacturing steps of the shed in template.

\begin{tabular}{|c|c|c|}
\hline Registro fotográfico & Descrição das etapas & Análise do processo \\
\hline & $\begin{array}{l}\text { Etapa } 10 \text { - O primeiro plano de } \\
\text { peças foi colocado e posicionado no } \\
\text { gabarito de modo que os conecto- } \\
\text { res metálicos se encontrassem no } \\
\text { mesmo ponto, fixando-os entre si } \\
\text { nos parafusos das esperas. }\end{array}$ & $\begin{array}{l}\text { Verificou-se dificuldade para o } \\
\text { adequado posicionamento das } \\
\text { peças metálicas na espera de } \\
\text { aroeira. }\end{array}$ \\
\hline & $\begin{array}{l}\text { Etapa } 11 \text { - Depois dos pilares } \\
\text { serem posicionados e travados, a } \\
\text { viga tripla é colocada por cima, } \\
\text { apoiando-se nos pilares e seguindo } \\
\text { demarcações no gabarito. }\end{array}$ & $\begin{array}{l}\text { O posicionamento da viga tripla } \\
\text { no gabarito foi realizado manu- } \\
\text { almente, sua posição exata foi } \\
\text { determinada através de marcações } \\
\text { nas tábuas de madeira. }\end{array}$ \\
\hline
\end{tabular}

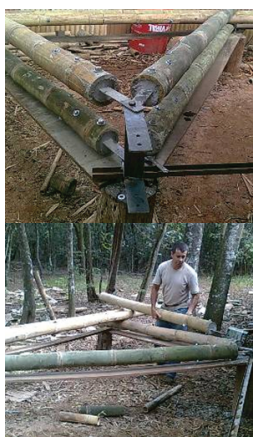

Etapa 12 - O terceiro plano formado por pilares foi posicionado por cima fazendo um "sanduíche" com a viga no meio. Eles foram posicionados e travados.
Guias foram instaladas para receber a última camada de peças de bambu.
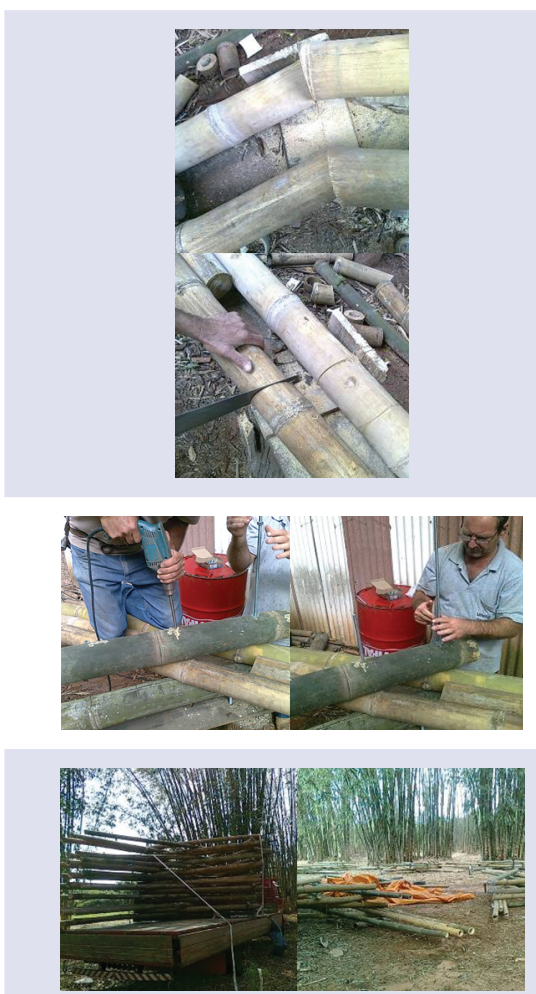

Etapa 13 - Foi efetuado o destopo em ângulo da cumeeira com o auxílio de uma linha guia para o corte. Em seguida, foi posicionada e travada de acordo com a delimitação dimensional do gabarito.
As peças que se encontram na cumeeira devem ter diâmetros próximos para obter um encaixe perfeito. Algumas uniões de cumeeira não se alinharam totalmente.
Etapa 14 - Foram cortadas as cumeeiras e posicionada adequadamente a viga tripla no gabarito. O componente é fixado com barra roscada de $1 / 2$ " nos pontos dos pilares inclinados duplos.

Etapa 15 - O pórtico foi divido em duas partes para facilitar sua retirada do gabarito, armazenamento e transporte.
Executado com furadeira manual, esta operação foi rápida e não apresentou problemas. Os furos foram executados da parte externa para a parte interna do pórtico.

Os componentes foram locados ao ar livre e cobertos por lona. Foram colocadas escoras para que os componentes não ficassem em contato direto com o solo. 


\section{CONCLUSÕES}

No presente trabalho, procurou-se descrever de forma sistemática todo o processo de préfabricação dos componentes em bambu para o Galpão Oficina do Assentamento Rural Horto de Aimorés. Como conclusões, podem ser destacados os seguintes aspectos no que se refere à elaboração do projeto executivo e ao processo de pré-fabricação. Primeiramente, cabe destacar que a viabilidade da produção de componentes pré-fabricados em bambu in natura depende fundamentalmente de quatro aspectos: a) Planejamento da cadeia produtiva da edificação desde as etapas de colheita, tratamento e preparação de infraestrutura da unidade de préfabricação; b) Elaboração do projeto executivo detalhado com pranchas de produção especificando todas as peças, ligações e interfaces; c) Capacitação e orientação da mão de obra de carpintaria; e d) Implementação de uma unidade de pré-fabricação dos componentes com adequada infraestrutura (bancadas, equipamentos manuais e manuais elétricos e gabaritos). No que se refere às etapas de processo executivo de produção e de pré-fabricação, pode-se apontar:

- verificou-se elevada agilidade no processo de préfabricação com o uso dos gabaritos de produção;

- constatou-se grande precisão na execução das ligações entre as peças com auxílio de gabaritos de furação;

- considerável padronização e controle de qualidade dos componentes; e

- relativa facilidade de assimilação do projeto executivo e do processo de montagem pela mão de obra (mesmo que não qualificada, para trabalhar com o bambu).

Por fim, constatou-se a eficiência e a praticidade do sistema construtivo considerando a peculiaridade e variabilidade das peças de bambu in natura.

\section{AGRADECIMENTOS}

Os autores deste trabalho agradecem aos Departamentos de Design, Engenharia Civil, Arquitetura, Urbanismo e Paisagismo e Engenharia Mecânica da UNESP/FEB Bauru/ SP. Agradecem também à FUNDUNESP, ao Laboratório Experimental de Bambu e ao
Laboratório de Processamento da Madeira, ao Projeto UNISOL - Universidade Solidária do Grupo Santander, aos alunos que participaram do projeto, aos moradores do assentamento rural Horto de Aimorés e a toda a equipe que participou do projeto.

\section{STATUS DA SUBMISSÃO}

Recebido: 01/09/2011

Aceito: 21/02/2012

Resumo publicado online: 22/03/2012

Artigo completo publicado: 30/06/2012

\section{AUTOR(ES) PARA CORRESPONDÊNCIA}

\section{Marco Antônio dos Reis Pereira}

Departamento de Engenharia Mecânica - DEM, Faculdade de Engenharia de Bauru - FEB, Universidade Estadual Paulista - UNESP, Av. Eng. Luiz Edmundo C. Coube, 14-01, CEP 17033-360, Bauru, SP, Brasil

e-mail: pereira@feb.unesp.br

\section{Maximiliano dos Anjos Azambuja}

Departamento de Engenharia Civil - DEC, Faculdade de Engenharia de Bauru - FEB, Universidade Estadual Paulista - UNESP, Av. Eng. Luiz Edmundo C. Coube, 14-01, CEP 17033-360, Bauru, SP, Brasil

e-mail: maximilianoazam@feb.unesp.br

\section{REFERENCIAS}

Barata TQF, Gandini JMD. Sistema Construtivo Préfabricado para a Sede do Imaflora, Piracicaba, SP. Madeira 2006; 19(1): 1-10.

Janssem JA. Design and building with bamboo. Eindhoven: Technical University of Eindhoven; 2000.

Pereira MAR, Beraldo AL. Bambu de corpo e alma. Canal 6 Editora; 2007.

Thiollent M. Metodologia da pesquisa-ação. São Paulo: Cortez; 1986.

Tripp D. Pesquisa-ação: uma introdução metodológica. Educação e Pesquisa 2005; 31(3): 443-466. http://dx.doi. org/10.1590/S1517-97022005000300009

Vélez S. Grow your own house. Switzerland: Vitra Design Museum; ZERI; 2000. 